
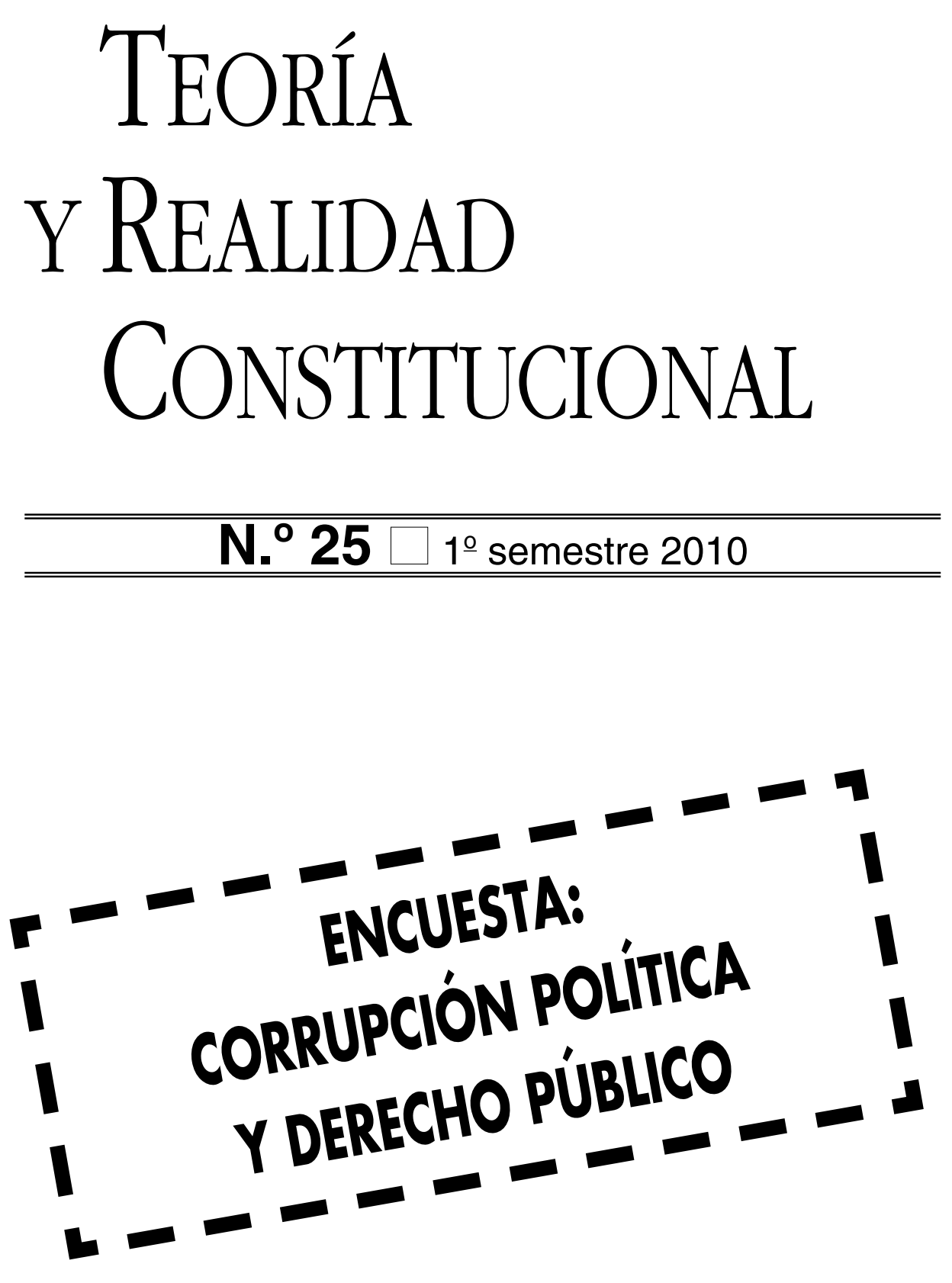


\title{
PANORÁMICA DE LA ACTUALIDAD POLÍTICA Y CONSTITUCIONAL ALEMANA (julio 2008 - diciembre 2009)
}

\author{
MARÍA ÁNGELES MARTÍN VIDA \\ Goethe-Universität Frankfurt am Main
}

\section{SUMARIO}

I. 2009, año electoral.

II. La segunda parta de la reforma del federalismo.

III. La Sentencia del Tribunal Constitucional Federal sobre el Tratado de Lisboa y sus efectos.

IV. Otras decisiones destacadas del Tribunal de Karlsruhe recaídas en los últimos meses.

V. Otros asuntos de relevancia constitucional que han sido objeto de discusión en este período.

Se presenta a continuación una visión panorámica, sin ánimo de exhaustividad, de los acontecimientos y debates más importantes que han marcado la actualidad política y constitucional de los últimos meses en Alemania.

\section{2009, AÑO ELECTORAL}

El período objeto de este comentario se inició con una sentencia del Tribunal Constitucional Federal (TCFA) de 3 de julio de 2008 (núms. de acta: 2 BvC 1/07 y 2 BvC 7/07) en la que éste había de decidir si una anomalía del sistema electoral alemán, en virtud de la cual puede darse el caso de que un partido pierda un escaño en las elecciones al Bundestag si recibe más de un determinado número de votos en un determinado Land y que lo gane si re- 
cibe menos ${ }^{1}$, es compatible con la Constitución, en la medida en que, por este "efecto del peso negativo de los votos", que se da con mucha frecuencia en las elecciones al Bundestag ${ }^{2}$, un votante puede verse obligado a no dar su voto al partido de su preferencia para evitar perjudicarle.

1 En las elecciones alemanas al Bundestag cada ciudadano dispone de dos votos. El primer voto sirve para elegir de forma directa, de acuerdo con un sistema mayoritario, a un candidato del distrito electoral de que se trate. El candidato elegido en el distrito mediante el primer voto logra en todo caso un escaño en el Bundestag, independientemente de lo que ocurra con los segundos votos. El segundo voto se asigna a la lista regional (es decir, a nivel de Land) de un partido (no hay listas federales). El reparto de escaños se lleva a cabo comenzando por los segundos votos, que se reparten a nivel federal según el sistema proporcional Hare-Niemeyer entre los diferentes partidos que han presentado sus candidaturas en los distintos Länder (primera fase). Una vez que se ha establecido cuántos escaños recibe cada partido en total de acuerdo con los segundos votos, se reparten los escaños proporcionalmente entre las diversas listas regionales de ese partido (segunda fase). De la cifra de escaños que corresponda a cada Land se restan los llamados "escaños directos" que el partido haya alcanzado en ese Land a través de los primeros votos y el resto se reparte según el orden establecido en las listas regionales (es decir, un candidato que haya obtenido un "escaño directo" por la vía de los primeros votos entra en todo caso en el Bundestag y desplaza a un candidato de la lista regional del partido). Puede, sin embargo ocurrir, que un partido haya alcanzado en un Land más "escaños directos" de los que de acuerdo con los segundos votos le corresponden en total en ese Land. El partido conserva pese a todo esos "escaños adicionales extraordinarios" (Überhangmandate) sin que se produzca una compensación con los otros partidos. Simplemente se incrementa el número total de Diputados en el Bundestag. Al repartir (proporcionalmente según el peso de los votos recibidos en cada Land) entre los distintos Länder los escaños que corresponden a un partido de acuerdo con los segundos votos ocurre con mucha frecuencia que un par de miles de votos deciden si un escaño de ese partido se le asigna a la lista de un Land o a la de otro. Si el escaño en cuestión deja de asignarse a ese partido en un Land en el que tiene "escaños adicionales extraordinarios" para asignarse a un Land donde no los tiene, no ocurre nada, porque el número de escaños de ese partido en cualquier caso se mantiene. Pero si el escaño en cuestión deja de asignarse a ese partido en un Land en el que no tiene "escaños extraordinarios" para asignarse matemáticamente (por haber tenido más segundos votos en ese Land que en el primero) a un Land en el que sí los hay, ese escaño de hecho se pierde: el partido tiene un escaño menos en el Bundestag a pesar de tener más votos en el Land al que el escaño se acaba asignando. Un resumen de esta complicada paradoja puede verse en FENDRICH, M.: "Paradoxien des Bundestags-Wahlsystem". Spektrum der Wissenschaft 2/1999, pp. 70 ss. (en www.wissenschaft-online.de/page/fe_seiten\&article_id=570654, consultada el 11 de junio de 2009).

2 Se calcula que en las elecciones del año 2005 el efecto del peso negativo de los votos alcanzó a más de seis millones de los votos emitidos ("Wahlrecht muss reformiert werden". Frankfurter Allgemeine Zeitung, 3 de julio de 2008, citando datos de la web www.wahlrecht.de). Qué efecto van a tener los votos no es a priori susceptible de ser previsto ni por los electores ni por los propios partidos, salvo que se dé excepcionalmente un supuesto de laboratorio como el que se dio en el Land de Sajonia en las elecciones generales al Bundestag del año 2005, donde hubo que repetir la votación en un distrito electoral de Dresden. Dado que ya se conocían los resultados en el resto de las circunscripciones, sí que fue posible prever el efecto negativo de los votos, y en función de eso planearon los partidos la campaña electoral para la repetición de la votación, llegando la CDU incluso a pedir a sus electores que no le diesen el segundo voto (véase al respecto HIPP, D.: "Wie die Stimme zu Gegenstimme wird". Spiegel Online, 2 de julio de 2008). El TCFA confirmó el 21 de julio de 2009 que el hecho de que se diese a conocer el resultado electoral en el resto de las circunscripciones antes de que se repitiese la votación en Dresden no vulnera la Ley Fundamental: las decisiones electorales tácticas representan, según el Tribunal, un modo perfectamente legítimo de participación del ciudadano en la formación de la 
En su sentencia de 3 de julio de 2008 el TCFA declaró que el Derecho electoral vigente para las elecciones al Bundestag es parcialmente inconstitucional por ese "efecto del peso negativo de los votos": el principio de la igualdad de voto se ve vulnerado porque cada voto ha de poder desarrollar un efecto positivo en favor del partido para el cual se emitió, lo cual no ocurre si con la emisión de un voto existe la posibilidad de perjudicar el fin electoral que se persigue; el carácter directo del voto se vulnera si el elector no puede saber si con su voto va a beneficiar o a perjudicar al partido y a los candidatos por él elegidos. El TCFA declaró pese a todo válidas las elecciones al Bundestag de 2005 por considerar que, si bien el defecto se reflejó en la composición del Bundestag, "prevalece el interés en que se conserve la situación en que la representación popular se ha conformado confiando en la constitucionalidad de la ley electoral", pero ordenó al legislador que reforme el Derecho electoral para suprimir este efecto y le dio de plazo hasta el 30 de junio de 2011, debido a la notable complejidad de la reforma ${ }^{3}$.

Las elecciones al Bundestag de septiembre de 2009 se celebraron según las normas electorales parcialmente declaradas inconstitucionales. La participación electoral fue de un $72 \%$, la más baja en las elecciones al Bundestag desde el nacimiento de la República Federal Alemana. La victoria fue para la Unión Democristiana (CDU/CSU), con un 33,8\% de los votos y un total de 239 escaños, seguida por el Partido Socialdemócrata (SPD), con un 23\% de los votos y 146 escaños, el peor resultado de su historia desde la Segunda Guerra Mundial. El Partido Liberal (FDP) recibió el 14,6\% de los votos y alcanzó 93 escaños, la Coalición de Izquierdas (Die Linke) un 11,9\% de los votos (76 escaños) y los Verdes un $10,7 \%$ de los votos (68 escaños). A pesar de los temores manifestados durante meses, los partidos democristianos y el FDP obtuvieron escaños suficientes como para sustentar a un Gobierno sin que la mayoría parlamentaria dependa exclusivamente de los "escaños adicionales extraordinarios", lo que podría haber provocado una notable crisis política ${ }^{4}$. Al final ha habido 24 "escaños adicionales extraordinarios", 21 para la CDU y 3 para el partido hermano bávaro CSU.

voluntad en un Estado democrático. El hecho de que se conociesen los resultados de las otras circunscripciones no supuso una limitación de la libertad de elección de los ciudadanos del distrito electoral de Dresden ni nadie se vio obligado a actuar de una determinada manera en contra de su voluntad, según el Tribunal de Karlsruhe.

3 En febrero de 2009 presentó el Grupo Parlamentario de Los Verdes un proyecto de ley para reformar la Ley Electoral Federal antes de las elecciones de septiembre, pero el mismo fue rechazado en el Bundestag el 3 de julio de 2009 con los votos de los partidos democristianos CDU/CSU, el partido socialdemócrata SPD (a pesar de sus simpatías hacia el proyecto) y el liberal FDP. Una crítica a la poca prisa que se están dando los partidos democristianos para reformar la ley electoral en este punto en el interesante comentario de BEHNKE, J.: "Parlament der zwei Geschwindigkeiten". Spiegel Online, 3 de julio de 2009.

4 Véase la discusión política en la semana previa a las elecciones: «SPD und Grüne warnen Merkel vor «illegitimer Merheit».. Frankfurter Allgemeine Zeitung, 20 de septiembre de 2009; y "Linkspartei kündigt rechtliche Schritte an". Frankfurter Allgemeine Zeitung, 21 de septiembre de 2009 . 
El 28 de octubre de 2009 Angela Merkel (CDU) fue elegida nuevamente Canciller Federal por el Bundestag con el apoyo de CDU, CSU y FDP. Días antes se había suscrito el Acuerdo de Coalición entre democristianos y liberales para la formación de Gobierno, en el que, entre otros puntos ${ }^{5}$, se preveía una bajada de impuestos para los ingresos medios y bajos y para las familias, así como una reforma del Impuesto de Sociedades y del Impuesto de Sucesiones. La bajada de impuestos prevista en el Acuerdo de Coalición se plasmó en la Ley para la Aceleración del Crecimiento Económico (Wachstumsbeschleunigungsgesetz), la primera ley importante del nuevo Gobierno Federal. Algunos Länder (incluso de los gobernados por CDU y FDP), que son quienes juntos con los municipios habrán previsiblemente de soportar en mayor medida la reducción de ingresos para las arcas públicas que la bajada de impuestos conlleva, amenazaron con bloquear la aprobación de la ley en el Bundesrat, e incluso se ha planteado la posibilidad por parte de Berlín y Bremen de presentar un recurso ante el Tribunal de Karlsruhe para que sea éste quien se pronuncie sobre la constitucionalidad de la misma y del endeudamiento al que forzará a los Länder (y también a la Federación) cuando se ponga en práctica ${ }^{6}$. La resistencia por parte de los Länder más pobres, sobre todo de Schleswig-Holstein, fue tan fuerte que la Canciller se vio obligada a hacer numerosas concesiones en forma de ayudas financieras para educación para conseguir evitar el bloqueo de la ley en la Segunda Cámara. La ley fue finalmente aprobada también en el Bundesrat y entró en vigor el 1 de enero de 2010.

El 23 de mayo de 2009 se celebró la elección del Presidente Federal por la Asamblea Federal (compuesta en un cincuenta por ciento por Diputados federales y en un cincuenta por ciento por delegados enviados por los Parlamentos regionales), que volvió a ganar Horst Köhler, el candidato de democristianos y liberales.

Hubo además elecciones europeas, que se celebraron el 7 de junio de 2009, con la victoria de los democristianos (CDU/CSU) con el 38\% de los votos, aunque con una pérdida notable de apoyos respecto a las elecciones celebradas cinco años antes. La participación en las elecciones europeas fue de algo menos del $43 \%$.

En el período que se comenta se han celebrado también en varios Länder elecciones regionales, cuyos resultados son decisivos para la articulación de las mayorías en el Bundesrat. La mayoría actual en el Bundesrat es para democristianos y liberales (treinta y siete votos, siendo necesarios treinta y cinco para sacar adelante una ley), pero es una mayoría inestable que podría perderse si en las elecciones regionales en Renania del Norte-Westfalia el 9 de mayo de 2010 la coalición de democristianos y liberales pierde la mayoría.

5 Véase al respecto el resumen de HENGST, B. y WEILAND, S.: "So will Schwarz-Gelb die Republik umbauen". Spiegel Online, 24 de octubre de 2009.

6 "Unionsländer rebellieren gegen schwarz-gelbe Steuersenkungen". Spiegel Online, 27 de octubre de 2009 . 
— En Baviera hubo elecciones en septiembre de 2008. Tras la histórica debacle del partido democristiano bávaro (CSU) gobierna, por primera vez en cuarenta y seis años, una coalición de democristianos y liberales bajo la presidencia de Horst Seehofer (CSU). La CSU no alcanzó, por primera vez en cuatro décadas, el cincuenta por ciento de los votos (se quedó en un 43,4\% al perder diecisiete puntos respecto a las anteriores elecciones). El Partido Socialdemócrata (SPD) logró en estas elecciones también el peor resultado electoral de su historia en Baviera.

- En Hesse hubo elecciones en enero de 2009, motivadas por una crisis institucional que adquirió tintes dramáticos cuando la candidata del SPD a las elecciones regionales que se habían celebrado en enero de 2008, intentó en noviembre de ese mismo año formar un Gobierno de minoría mediante una coalición de su partido con los Verdes que contaría con el apoyo del Partido de Izquierda, vulnerando de esta manera su promesa electoral de no apoyarse de ningún modo en el Partido de Izquierda para formar Gobierno. En el día previo a la elección de Ypsilanti como Presidenta de Hesse, cuatro Diputados regionales de su partido afirmaron públicamente por sorpresa su intención de abandonar el Grupo Parlamentario y de no dar el voto a la candidata, lo que en la práctica le impedía alcanzar la mayoría necesaria para ser elegida Presidenta y rompía el acuerdo logrado con los Verdes. Ante la imposibilidad de formar un Gobierno estable en Hesse, hubo que convocar nuevas elecciones, que se celebraron el 18 de enero de 2009 y que dieron la victoria a la CDU que gobierna actualmente en coalición con el FDP bajo la Presidencia de Roland Koch (CDU). El SPD logró en estas elecciones su peor resultado en la historia de Hesse.

- En Sajonia se celebraron elecciones el 30 de agosto de 2009, tras las cuales gobierna una coalición de CDU y FDP bajo la dirección de Stanislaw Tillisch (CDU). El partido de extrema derecha NPD conserva ocho Diputados en el Parlamento de este Land.

- También en Turingia hubo elecciones regionales el 30 de agosto de 2009. Desde octubre de 2009 gobiernan en coalición CDU y SPD bajo la Presidencia de Christine Lieberknecht (CDU). El partido de extrema derecha NPD no logró representación en el Parlamento del Land.

- En el Sarre hubo también elecciones regionales el 30 de agosto de 2009 tras las cuales se ha formado el primer Gobierno de coalición de la historia de la República Federal entre CDU, FDP y los Verdes. Presidente del Land sigue siendo Peter Müller (CDU).

- El 27 de septiembre de 2009 se celebraron elecciones en Brandemburgo. El SPD volvió a ser el partido más votado y el Partido de Izquierda la segunda fuerza del Land, mientras que el partido de extrema derecha DVU salió del Parlamento regional. Después de diez años de Gobierno de coalición entre SPD y CDU gobierna en Brandemburgo desde el 6 de noviembre el SPD en coalición con el Partido de Izquierda bajo la Presidencia de Matthias Platzeck (SPD).

— En Schleswig-Holstein el Presidente del Land, Peter Harry Carstensen 
(CDU), se vio obligado a usar la técnica de perder una cuestión de confianza para poder disolver el Parlamento regional en julio de 2009 y convocar elecciones coincidentes con las generales al Bundestag, a la vista de la imposibilidad de seguir gobernando con el que hasta entonces había sido su socio en el Gobierno del Land, el SPD. Tras las elecciones de 27 septiembre de 2009, el partido democristiano (CDU) sigue siendo la fuerza más votada y ahora gobierna en coalición con los liberales (FDP) nuevamente bajo la Presidencia de Carstensen?

\section{LA SEGUNDA PARTE DE LA REFORMA DEL FEDERALISMO}

El 29 de mayo de 2009, tras dos años de trabajo, se aprobó en el Bundestag, y el 12 de junio en el Bundesrat, con la mayoría de dos tercios necesaria para la correspondiente reforma constitucional, la segunda parte de la llamada "reforma del federalismo", que entrará en vigor el 1 de enero de $2011^{8}$. De acuerdo con el nuevo artículo 109.3 y 4 GG, desde el año 2020 como muy tarde los Länder no podrán en principio asumir nuevas deudas (salvo en caso de crisis económica9 o de catástrofe), mientras que la Federación desde 2016 sólo podrá endeudarse en circunstancias normales hasta un máximo anual del 0,35\% del Producto Interior Bruto $^{10}$ (lo que actualmente serían unos nueve mil millones de euros). Todos se obligan a ir reduciendo hasta esas fechas el nivel de endeudamiento. En el caso de la Federación eso supondrá, según cálculos del nuevo Ministro de Hacienda Schäuble (CDU), tener que recortar gastos en una cuantía de diez mil millones de euros al año entre 2011 y 2016. Se crea además (nuevo art. 109a GG) un Consejo encargado de vigilar el cumplimiento de este freno a la posibilidad de endeudamiento del Estado y de alertar tempranamente de posibles problemas presupuestarios en la Federación o los Länder. La reforma constitucional permite

7 La mayoría de Gobierno de CDU y FDP en Schleswig-Holstein se sustenta sobre tres "escaños adicionales extraordinarios" no compensados; de hecho, el resto de los partidos obtuvieron en total más segundos votos (en un sistema electoral parecido al de las elecciones generales al Bundestag) que CDU y FDP. El reparto de escaños ha sido objeto de recurso ante el Tribunal Constitucional del Land. Sobre esta cuestión véase PERGANDE, F. "Überhang und Ausgleich". Frankfurter Allgemeine Zeitung, 6 de octubre de 2009; y "Dänische Minderheitspartei ebnet Carstensen den Weg", Spiegel Online, 28 de septiembre de 2009.

8 Sobre la segunda parte de la reforma del federalismo véanse KORIOTH, S.: "Das neue Staatsschuldenrecht - zur zweiten Stufe der Föderalismusreform». Juristenzeitung, núm. 14, 2009, pp. 729 ss.; SEILER, Ch.: «Konsolidierung der Staatsfinanzen mithilfe der neuen Schuldnregel", ibidem, pp. 721 ss.; y HÄDE, U.: "Sobre la reforma del federalismo en Alemania”. Teoría y Realidad Constitucional, núm. 24, 2009, pp. 515 ss.

9 En caso de crisis económica los Länder pueden asumir deudas que se obligan a compensar en la fase de bonanza económica.

10 En fases de crisis económica la Federación también puede endeudarse por encima de ese límite, pero se obliga a compensar en la fase de bonanza las deudas asumidas en exceso. En caso de "catástrofe natural u otros sucesos extraordinarios" el Bundestag podrá fijar por mayoría un límite más elevado a la capacidad de endeudamiento de la Federación 
además a la Federación, en caso de catástrofes naturales o situaciones extraordinarias de necesidad, conceder ayudas financieras a los Länder y a los municipios para cubrir ciertas inversiones, aunque sean éstos competentes para la realización de la tarea en cuestión ${ }^{11}$.

Con esta segunda parte de la reforma del federalismo se sustituye el artículo 115 GG, que limita la posibilidad de asunción de deudas por parte de la Federación, vinculando su cuantía a la de las inversiones (en la práctica eso son unos veinticinco mil millones de euros anuales), que no ha podido evitar la elevada deuda a la que actualmente tiene que hacer frente el Estado alemán ${ }^{12}$. La nueva disposición amenaza, sin embargo, la propia existencia de los Länder en una situación financiera más complicada, en concreto Bremen, el Sarre, SajoniaAnhalt, Berlín y Schleswig-Holstein, sobre todo si se tiene en cuenta que los Länder no gozan de autonomía impositiva. La Federación y los otros Länder han asumido por ello la obligación de contribuir con ochocientos millones anuales de euros a reducir durante los próximos nueve años la deuda de estos Länder en situación financiera crítica (art. 143d.2 y 3 GG) ${ }^{13}$, siempre que éstos limiten la asunción de nuevas deudas, para que estén en condiciones de cumplir con sus nuevas obligaciones constitucionales a partir del año 2020.

Lo que no se ha podido conseguir con la segunda parte de la "reforma del federalismo" ha sido la por algunos pretendida reducción (vía fusión) del número de Estados federados que forman la República Federal de Alemania ni una reforma del procedimiento de toma de decisiones en el Bundesrat ni, como se incorporó incluso al Acuerdo de Coalición de 2005, una reforma en profundidad de las relaciones financieras entre la Federación y los Länder.

\section{LA SENTENCIA DEL TRIBUNAL CONSTITUCIONAL FEDERAL SOBRE EL TRATADO DE LISBOA Y SUS EFECTOS}

El TCFA declaró en su sentencia de 30 de junio de 2009 compatible con la Ley Fundamental la Ley alemana de Ratificación del Tratado de Lisboa ${ }^{14}$ y la

11 La primera parte de la reforma del federalismo prohibía sin excepción a la Federación conceder ayudas financieras a los Länder o a los municipios cuando éstos fuesen competentes para la realización de la tarea que se pretendía cofinanciar, para evitar que la Federación se inmiscuyese de este modo en la competencia de los otros entes.

12 En los Länder se aplican reglas similares. Según afirmaciones del que hasta octubre fue Ministro de Hacienda Steinbrück (SPD) ("Steinbrück verteidigt Schuldenbremse". Spiegel Online, 27 de marzo de 2009), desde 1980 hasta hoy la deuda de la Federación ha pasado de ciento veinte mil a novecientos sesenta mil millones de euros, y supera con creces los límites establecidos en el Pacto de Estabilidad europeo.

13 Con lo que, en definitiva, apuntan los críticos de este acuerdo, se está premiando a quienes, independientemente de su riqueza o su potencial económico, no han manejado bien sus finanzas y castigando a quienes, con más o menos medios, sí lo han hecho.

14 Esta ley autoriza al Presidente alemán a firmar el documento de ratificación del Tratado e incorpora al ordenamiento alemán el contenido del Tratado de Lisboa al entrar éste en vigor. 
Ley de Reforma de la Ley Fundamenta ${ }^{15}$, pero inconstitucional la Ley de Acompañamiento (de Ampliación y Reforzamiento de los Derechos del Bundestag y del Bundesrat en Asuntos Relativos a la UE) al considerar que las posibilidades de participación de Bundestag y Bundesrat en la toma de decisiones a nivel comunitario previstas en esta ley no satisfacían las exigencias de la Ley Fundamental ${ }^{16}$.

El Tribunal de Karlsruhe considera que la Ley de Acompañamiento vulnera el artículo 23.1 GG, precepto que regula la participación de Alemania en la integración europea de acuerdo con estándares democráticos ${ }^{17}$, interpretado a la luz del artículo 79.3 GG, donde se establecen los límites a la actuación del poder de reforma de la Constitución ${ }^{18}$. El Tribunal critica en concreto la (escasa) participación del Parlamento alemán en este proceso. Cualquier modificación material del Tratado que pueda llevarse a cabo sin seguir el procedimiento de ratificación por parte de los órganos constitucionales alemanes ha de contar según el TCFA, por exigencias del artículo 23.1 GG, con el consentimiento expreso de los órganos legislativos (Bundestag y, en su caso, según la materia de que se trate, Bundesrat), de modo que el representante alemán en el Consejo no puede emitir su voto a menos que y hasta que el Parlamento alemán se haya pronunciado, y habrá de hacerlo en el sentido manifestado por

15 La Ley de Reforma de la Ley Fundamental introduce en el artículo 23.1 GG el recurso de subsidiariedad" ante el TJUE, a través del cual los Parlamentos nacionales podrán defenderse frente a posibles violaciones de este principio por parte de la UE. También se reforma el artículo 93.1.2 GG.

16 La firma definitiva de estas leyes por el Presidente alemán estaba pendiente de la sentencia del TCFA.

$17 \mathrm{El}$ artículo $38.1 \mathrm{GG}$ reconoce el derecho al voto directo, libre, igual y secreto en las elecciones al Bundestag y garantiza a las ciudadanos el derecho a participar a través del sufragio en la función legislativa e influir a través de sus representantes parlamentarios en el ejercicio de la autoridad estatal, lo cual es un elemento esencial del principio democrático que, por esta vía, queda también protegido. De acuerdo, además, con el artículo 23.1 GG, el proceso de integración europea ha de respetar, entre otros, el principio democrático. El Tribunal de Karlsruhe reconoce en la sentencia de 30 de junio de 2009 la posibilidad de que cualquier ciudadano alemán acuda a él, por la vía del artículo 38.1 GG o incluso por la vía del artículo 23.1 en conexión con el artículo 79.3 GG, frente a actos comunitarios en los que la UE se extralimite en las competencias que le reconocen los Tratados e invita al legislador a crear nuevos procedimientos ante el Tribunal especialmente pensados para controlar las actuaciones ultra vires de las instituciones comunitarias y para controlar posibles vulneraciones de la identidad constitucional alemana (apartado 241 de la sentencia). Sobre las dificultades para articular este control por las vías actualmente previstas en la Ley Fundamental véanse GÄRDITZ, K.F. y HILLGRUBER, Ch.: "Volkssouveranität und Demokratie ernst genommen - Zum Lissabon-Urteil des BVerfG». Juristenzeitung, núm. 18, 2009, p. 874 .

$18 \mathrm{Si}$ bien es más que dudoso que esta disposición, pensada para evitar que el poder de reforma pueda llevar a Alemania de nuevo a la dictadura y a un sistema político que vulnere la dignidad humana, esté pensado para proteger la soberanía del Estado alemán en el marco del proceso de integración europea, como destacan HALBERSTAM, D. y MÖLLERS, Ch.: "The German Constitutional Court says "Ja zu Deutschland!’m. German Law Journal, núm. 8, vol. 10, 2009, p. 1254. Muy crítico con los razonamientos del Tribunal en relación a la "cláusula de eternidad" SCHÖNBERGER, Ch.: "Lisbon in Karlsruhe: Maastricht's Epigones at Sea”, ibidem, en especial pp. 1208 ss. 
éste. El mero silencio del Bundestag (y, en su caso, del Bundesrat) en los casos en los que el Derecho primario de la UE les reconoce un derecho de veto (por ejemplo, respecto a la utilización de determinadas "cláusulas-pasarela") no satisface, según el Tribunal de Karlsruhe, las exigencias que le impone la responsabilidad que le corresponde en el proceso de integración europea.

El TCFA establece con esta sentencia además claros límites a la integración europea, que no puede privar al Estado alemán de todo margen de decisión política y de toda su capacidad para seguir diseñando los aspectos fundamentales de las esferas vitales cultural, social y económica en Alemania. El Tribunal alude con ello en especial al espacio privado de autorresponsabilidad protegido por los derechos fundamentales, a la seguridad personal y social, y a las decisiones políticas que dependen de una manera particular de condicionantes culturales, históricos y lingüísticos y que se construyen mediante el debate y el razonamiento de una opinión pública política organizada parlamentariamente y con partidos políticos (apartado 249 de la sentencia). La soberanía implica que el Estado conserve en todo caso un núcleo fundamental de tareas y estructuras, sin las cuales dejaría de ser Estado soberano. Así, el Estado alemán ha de poder seguir adoptando decisiones en una serie de materias que el Tribunal enumera expresamente: ciudadanía; guerra y paz (monopolio del uso de la fuerza civil y militar); gastos e ingresos (incluida la asunción de deudas); injerencias particularmente intensas en los derechos fundamentales (como la privación de libertad y, en general, el Derecho penal tanto material como procesal); lengua, configuración de las relaciones familiares y educativas, regulación de la libertad religiosa e ideológica y de opinión, prensa o reunión (apartado 249). El ordenamiento jurídico comunitario no deja de ser, en opinión del TCFA, un ordenamiento derivado del de los Estados miembros, que siguen siendo los "dueños de los Tratados". Si Alemania desea ir más allá, renunciar en parte a su identidad constitucional, atribuir a la Unión Europea la "competencia de las competencias" e integrarse en un "Estado federal europeo" (que sería incompatible con la Ley Fundamental y que no es, en cualquier caso, lo que resulta del Tratado de Lisboa) el único que puede tomar tal decisión es el pueblo alemán a través de un nuevo acto del poder constituyente (Art. $146 \mathrm{GG})^{19}$. Mientras eso no ocurra, Alemania ha de moverse dentro de los límites que le marca en esta sentencia el TCFA y cuya garantía viene dada por la posibilidad del Tribunal de Karlsruhe de controlar él mismo, declarando inaplicables en su caso los actos comunitarios de que se trate (apartado 241 de la sentencia), posibles vulneraciones del principio de la atribución limitada de competencias a la Unión Europea y posibles injerencias en el núcleo intangible de la identidad constitucional que ha de conservar el Estado alemán ${ }^{20}$.

19 Apartados 228 y 347 de la sentencia.

20 Sobre este control, SCHORKOPF, F.: "The European Union as an Association of Sovereign States: Karlsruhe's Ruling on the Treaty of Lisbon". German Law Journal, núm. 9, vol. 10, 2009, pp. 1231 ss. 
El TCFA señaló en su sentencia que el Presidente alemán no podría ratificar el Tratado de Lisboa hasta que no se corrigiesen los aspectos inconstitucionales de la Ley de Acompañamiento. Así, durante todo el mes de agosto de 2009 el Parlamento alemán estuvo trabajando en una reforma de la Ley de Acompañamiento para adaptarla a lo dicho por el TCFA en la sentencia, reforma que se consiguió aprobar, como se pretendía, en septiembre de 2009, antes de las elecciones generales y antes del referéndum irlandés sobre el Tratado de Lisboa, aunque después de una muy dura discusión entre los dos partidos democristianos CDU y CSU ${ }^{21}$.

La nueva Ley de Ampliación y Reforzamiento de los Derechos del Bundestag y del Bundesrat en Asuntos Relativos a la UE, aprobada por el Bundestag el 8 de septiembre de 2009 y por el Bundesrat el 18 del mismo mes, incorpora en su artículo 1 la llamada "Ley sobre la Asunción de Responsabilidad de Bundestag y Bundesrat en el Proceso de Integración en asuntos de la $\mathrm{UE}^{22}$, que contempla la obligatoriedad de una ley del Bundestag y, cuando la reforma afecte a competencias de los Länder, también del Bundesrat cuando la decisión que el representante alemán haya de tomar en el Consejo Europeo suponga una reforma de los Tratados por la vía del procedimiento simplificado (art. 48.6 TUE) ${ }^{23}$. Asimismo, cuando los Estados miembros pretendan comunitarizar determinadas materias no contempladas en los Tratados pero

21 El partido bávaro CSU pretendía recoger en la Ley de Acompañamiento, siguiendo el modelo austríaco, la vinculatoriedad para el Gobierno Federal de las tomas de posición del Bundestag y del Bundesrat en materias de política comunitaria, lo que, según los críticos de esta postura (entre ellos la posición oficial del partido hermano CDU) conduciría a un bloqueo en la capacidad de maniobra del Gobierno Federal en las reuniones del Consejo de la Unión Europea. Pretendía además que se adjuntase al Tratado de Lisboa una declaración en la que se afirmase que el Tratado tiene validez y es aplicable en Alemania sólo en el sentido de lo dispuesto en la sentencia del TCFA de 30 de junio de 2009 (a favor de la solución de incorporar una reserva al Tratado también GÄRDITZ, K.F. y HILLGRUBER, C., op. cit., p. 878); que se contemplase expresamente la posibilidad del Gobierno Federal, del Bundesrat y del Bundestag de recurrir ante el Tribunal de Karlsruhe las normas comunitarias ultra vires; y que las nuevas adhesiones a la UE hubiesen de ser confirmadas en Alemania en referéndum, para lo cual sería necesaria una reforma de la Ley Fundamental de Bonn. Al final la Canciller Merkel se comprometió frente a la CSU a explicar a sus colegas de otros Estados europeos en la siguiente cumbre comunitaria la posición alemana respecto al Tratado de Lisboa en lugar de incluir una declaración como la pretendida por los democristianos bávaros. Por otro lado, en la legislatura que acaba de comenzar se analizará el posible diseño de un nuevo recurso ante el TCFA para el control de normas comunitarias ultra vires.

22 BGBl. I 2009, 3022. El texto de esta ley, en alemán, en http://bundesrecht.juris.de/bundes$\mathrm{recht} / \mathrm{intvg} /$ gesamt.pdf, consultada el 6 de enero de 2010. Sobre esta ley y las demás que se aprobaron en este paquete puede verse el análisis de LECHELER, H.: "Die Mitwirkungsgesetzgebung an der europäischen Integration vor und nach dem Urteil des BVerfG zum Lissabon-Vertrag". Juristenzeitung, núm. 23, 2009, pp. 1156 ss.

23 El Tratado de Lisboa prevé un procedimiento general simplificado de reforma mediante una resolución unánime del Consejo (Europeo), que entrará en vigor una vez que haya sido aprobada por los Estados miembros de conformidad con sus respectivas normas constitucionales, para la parte del Tratado sobre el Funcionamiento de la Unión Europea en la que se describen las políticas y acciones internas de la Unión Europea (art. 48.6 TUE) y para una serie de materias específicas (art. 42.2 TUE, arts. 25.2, 218.8, 223.1, 262 y 311.3 TFUE). 
cuya europeización se considere necesaria para alcanzar los fines perseguidos por la UE (cláusula de flexibilidad, art. 352 TFUE) será imprescindible una ley de Bundestag y Bundesrat. También en los supuestos en que se trata de hacer uso de las "cláusulas-pasarela" previstas en el Tratado ${ }^{24}$ ha de esperar el representante alemán ante el Consejo a que el Bundestag y, en su caso, el Bundesrat definan expresamente la posición alemana. Sólo en la medida en que las "cláusulas-pasarela" se limiten a ámbitos concretos suficientemente determinados por los Tratados no será imprescindible una ley a los efectos del artículo 23 GG, sino que bastará con una resolución de otra naturaleza. También mediante resolución pueden el Bundestag y el Bundesrat obligar al representante alemán ante el Consejo, según la nueva Ley, a hacer uso del "freno de emergencia", es decir, a que de una propuesta legislativa en materia de Derecho penal o de seguridad social se ocupe el Consejo Europeo y no el Consejo de Ministros de la UE cuando el ordenamiento penal nacional o el equilibrio del sistema nacional de Seguridad Social puedan estar en peligro si se adopta la resolución de que en cada caso se trate (arts. 48.2, 82.3 y 83.3 TFUE $)^{25}$.

La Ley sobre la Responsabilidad en el Proceso de Integración Europea y las otras dos leyes aprobadas junto a la misma detallan también las obligaciones de información que el Gobierno Federal tiene respecto al Bundestag y a los Länder en relación a los asuntos de la UE. En la Ley de Reforma de la Ley sobre la Cooperación entre el Gobierno Federal y el Bundestag alemán en asuntos de la UE (BGBl. I 2009, 3026) se reconoce al Bundestag la posibilidad de manifestar su posición respecto a cualquier negociación en curso dentro de la UE. Si el Gobierno Federal no consigue hacer valer ante la UE la posición defendida por el Bundestag, habrá de dar explicaciones a éste sin dilación y de forma detallada. El Bundestag ha de manifestar además formalmente su consentimiento al inicio de negociaciones con posibles candidatos a acceder a la Unión Europea y al inicio de negociaciones para una posible reforma de los Tratados comunitarios. A los Länder también se les reconoce en la Ley de Reforma de la Ley sobre la Cooperación entre el Gobierno Federal y

24 Según el artículo 48.7 TUE, el Consejo Europeo puede acordar pasar de la unanimidad a la toma de decisiones por mayoría cualificada, o del procedimiento legislativo especial al ordinario ("Cláusula-pasarela" general). Esta decisión entra en vigor cuando en un plazo de seis meses ningún Parlamento nacional se haya opuesto a ella. Hay una "cláusula-pasarela" similar específica para el Derecho de familia (art. 81.3 TFUE). En el caso del resto de las "cláusulas-pasarela" (art. 31.3 TUE, arts. 153.2, 192.2, 312.2 y 333.2 TFUE) el Consejo (Europeo) puede adoptar una decisión de ese tipo sin que los Parlamentos nacionales tengan un derecho de veto.

25 De hecho es que el representante alemán sólo podrá hacer uso, según el TCFA, de este "freno de emergencia" si el Bundestag y, en su caso, el Bundesrat lo conminan a ello (contrario a esta interpretación CLASSEN, C. D.: "Legitime Stärkung des Bundestages oder verfassungsrechtliches Prokrustesbett? - Zum Urteil des BVerfG zum Vertrag von Lissabon". Juristenzeitung, núm. 18, 2009, p. 886 - una traducción de este artículo al castellano en este número de Teoría y Realidad Constitucional). Sobre el curioso caso del "freno de emergencia" y las paradojas de la sentencia del Tribunal Constitucional en este punto, HALBERSTAM, D. y MÖLLERS, C., op. cit., pp. 1243 y siguiente. 
los Länder en asuntos de la UE (BGBl. I 2009, 3031) el derecho, cuando se trate de cuestiones que afecten a competencias propias, de emitir a través del Bundesrat una toma de posición e impartir indicaciones al Gobierno Federal. Un apartamiento de las mismas en el transcurso de las negociaciones comunitarias habrá de ser justificada por el Gobierno.

El Presidente de la República Federal Alemana ratificó finalmente el Tratado de Lisboa el 25 de septiembre de 2009.

\section{OTRAS DECISIONES IMPORTANTES DEL TRIBUNAL DE KARLSRUHE RECAIIDAS EN LOS ÚLTIMOS MESES}

a) El 30 de julio de 2008 el TCFA dejó sin efecto la prohibición de fumar en los locales de una sola sala y exigió a los Länder que sus leyes fuesen objeto de mejoras legislativas antes del fin de $2009^{26}$. En su sentencia (núms. de acta: 1 BvR 3262/07 y otros) declaró el Tribunal que una prohibición estricta y absoluta de fumar en todos los locales (como la que existía en Baviera ${ }^{27}$ ) y una consecuente "protección absoluta de la salud" (a la que se califica como de "bien comunitario extraordinariamente importante") sería compatible con la Ley Fundamental, pero que, desde el momento en que las leyes de los Länder contemplen excepciones para algunos locales, hay que permitir que los locales de una sola sala puedan optar por que se fume en ellos. Las leyes de los Länder Baden-Württemberg y Berlín, objeto de los recursos ante el Tribunal, fueron declaradas en este sentido parcialmente inconstitucionales por vulnerar el principio de proporcionalidad. En septiembre de 2008 los Ministros de Sanidad de la Federación y de los Länder se pusieron de acuerdo para dotar a las nuevas leyes de un contenido básico uniforme: no se establecerá una prohibición absoluta de fumar sino que se contemplarán excepciones a la prohibición, que regirán tanto en los locales grandes (que podrán habilitar salas especiales separadas para fumadores) como para los de una sola sala de menos de setenta y cinco metros cuadrados (que podrán permitir que se fume en ellos siempre que no se coma en los mismos y no se permita el acceso a menores de edad). Incluso Baviera suavizó la prohibición absoluta de fumar y modificó en enero de 2009 su ley en este sentido. En una decisión de 1 de octubre de 2009 (núm. de acta: 1 BvR 2054/09) confirmó el Tribunal Constitucional Federal la constitucionalidad de la nueva ley bávara. Ahora una ini-

26 Véase el comentario a esta sentencia de MICHAEL, L.: "Folgerichtigkeit als Wettbewerbsgleichheit". Juristenzeitung, núm. 18, 2008, pp. 875 ss.

27 El 12 de agosto de 2008 el TCFA no admitió a trámite dos recursos de amparo contra la ley bávara, tal como cabía esperar después de la sentencia del 30 de julio (núms. de acta: 1 BvR 3198/07 y 1 BvR 1431/08). El TCFA no apreció una posible incompatibilidad constitucional por el hecho de que en Baviera se permita la constitución de "clubes de fumadores", posibilidad de la que se ha hecho amplio uso en este Land. 
ciativa legislativa popular, apoyada por más de un millón de ciudadanos, ha conseguido que el Parlamento bávaro tenga que abordar una reforma para volver a endurecer la ley suprimiendo cualquier posible excepción a la prohibición de fumar en locales públicos. Si el Parlamento no aprueba la reforma propuesta por la iniciativa popular, se habrá de convocar un referéndum para que los bávaros decidan ${ }^{28}$.

b) El 3 de marzo de 2009 dictó el TCFA una sentencia (núms. de acta: 2 $\mathrm{BvC} 3 / 07$ y $2 \mathrm{BvC} 4 / 07$ ) en la que resolvió un recurso de amparo presentado por dos particulares y declaró inadmisible el uso de ordenadores electorales en las elecciones al Bundestag porque la técnica actual adolece de numerosos defectos y es difícilmente controlable, lo que la hace susceptible de manipulaciones $^{29}$. El empleo de ordenadores electorales (hasta mil ochocientos de ellos se utilizaron en las elecciones al Bundestag de 2005 a través de los cuales unos dos millones de personas emitieron su voto) contradicen el principio de la publicidad de las elecciones. Las elecciones de 2005, sin embargo, no se anulan al no haberse demostrado ninguna manipulación o error concretos debidos al uso de los ordenadores. El TCFA no excluye, sin embargo, el uso de ordenadores electorales en el futuro, una vez que la técnica se haya depurado. Requisito sería en cualquier caso que quede constancia en papel (mediante un recibo o similar) de los votos emitidos para poder controlar a posteriori, en caso de que cualquier ciudadano lo solicite, posibles irregularidades.

c) El 23 de julio de 2009 se hizo pública la sentencia en la que el TCFA resolvía positivamente ${ }^{30}$ un recurso de los Grupos Parlamentarios del Partido Liberal (FDP), los Verdes y el Partido de Izquierda para que no se impidiese la actuación de la Comisión que investigaba las actividades de los Servicios Secretos Federales (Bundesnachrichtendienst, BND). En esa sentencia, hecha pública una vez que la Comisión de investigación ya había concluido su trabajo y había quedado disuelta, se afirmó que el Gobierno Federal había vulnerado indebidamente los derechos de información y de investigación del Bundestag al obstaculizar el trabajo de la Comisión parlamentaria (prohibiendo a los miembros de los servicios secretos declarar como testigos ante la Comisión o impidiéndole el acceso a las actas solicitadas), sin que quepa justificar esa actuación apelando al "bien del Estado" o a la "autorresponsabilidad del Ejecutivo". El 30 de julio de 2009 se publicó otra sentencia del TCFA ${ }^{31}$ en la que se reconoce el derecho de los miembros del Bundestag a recibir información del Gobierno Federal acerca de si están siendo objeto de investi-

28 Cfr. "Bayern drücken Seehofer Volksentscheid aufs Auge». Spiegel Online, 3 de diciembre de 2009.

29 Véase el comentario a esta sentencia de S. SCHIEDERMAIR en Juristenzeitung, núm. 11, 2009 , pp. 572.

30 Sentencia de 17 de junio de 2009, núm. de acta: 2 BvE 3/07. Sobre esta sentencia véase GATHMANN, F. y HIPP, D.: "Verfassungsrichter rügen Informationspolitik der Regierung”. Spiegel Online, 23 de julio de 2009.

31 Sentencia de 1 de julio de 2009, núm. de acta: 2 BvE 5/06. 
gación por parte de los servicios secretos, sin que el Gobierno pueda rechazar aportar tales informaciones pues ello vulneraría el derecho a la información del Parlamento y de sus miembros frente al Gobierno Federal ${ }^{32}$.

d) El 1 de diciembre de 2009 el TCFA dictó una sentencia (núm. de acta: 1 BvR 2857/07 y otros) en la que declaró contraria a la Ley Fundamental de Bonn la apertura de comercios los cuatro domingos de Adviento en el Land Berlín. Una vez que los Länder asumieron, tras la primera parte de la reforma del federalismo, la competencia en materia de horario de apertura de comercios, decidió el Land Berlín, en el que gobierna una coalición de SPD y el Partido de Izquierda, que sus comercios pudiesen abrir diez domingos al año, incluidos los cuatro domingos de Adviento. Contra esta ley recurrieron en amparo la Iglesia Católica y la Iglesia Evangélica por considerar que vulneraba el mandato constitucional de que los domingos y días festivos sean días de descanso, recogido en el artículo 139 de la Constitución de Weimar, incorporado a la Ley Fundamental de Bonn ${ }^{33}$. El TCFA afirma que la apertura de los comercios los cuatro domingos de Adviento vulnera la protección constitucional del domingo, sin que ello pueda quedar justificado atendiendo a criterios puramente económicos, mientras que la apertura otros seis domingos al año no resulta inconstitucional, aunque ha de limitarse al horario de 13 a 20 horas. El domingo es, en opinión de los Magistrados, un día de descanso, no sólo por motivos religiosos, sino que también ha de servir para permitir el reposo personal de los trabajadores y abrirles espacios de participación en la vida social.

\section{OTROS ASUNTOS DE RELEVANCIA CONSTITUCIONAL QUE HAN SIDO OBJETO DE DISCUSIÓN EN ESTE PERÍODO}

- En el ámbito de la lucha antiterrorista hay que destacar la aprobación de la nueva Ley reguladora de la Agencia Federal contra el Crimen (Bundeskriminalamt, en adelante BKA) ${ }^{34}$. En diciembre de 2008 se aprobó esta ley,

32 El 23 de julio de 2009 había entrado en vigor una reforma de la Ley Fundamental para incorporar a través de su artículo 45d una referencia expresa al órgano parlamentario de control de los servicios secretos a la misma y dotarlo de mayores derechos. A sus miembros se les permitirá en el futuro acceder sin aviso previo a las actas de los servicios secretos que además se les habrán de entregar ahora en original si así lo solicitan. Se amplian asimismo las posibilidades de interrogar a los miembros de los servicios secretos y al Gobierno en relación a las actividades de éstos. No será imprescindible solicitar permiso a los superiores para poder interrogar a los colaboradores. El Gobierno queda obligado a cumplir sin demora su obligación de remitir al órgano parlamentario de control informes periódicos sobre las actividades de los servicios secretos.

33 Ese artículo dice literalmente: «El domingo y los días festivos reconocidos oficialmente quedarán protegidos por ley como días de descanso laboral y de recogimiento espiritual" (traducción en http://constitucion.rediris.es/legis/legextr/ConstitucionAlemana.html).

34 Sobre los antecedentes, véase MARTÍN VIDA, M.A.: "Panorámica de la actualidad política y constitucional alemana desde enero de 2007 a junio de 2008". Teoría y Realidad Constitucional, núm. 22, 2008, pp. 359 ss. El BKA es competente para la lucha contra el terrorismo internacional, incluidas las tareas de prevención de delitos, cuando el peligro alcanza a más de un Land, cuan- 
que entró en vigor el 1 de enero de 2009. El registro online de sistemas informáticos se permite en esta ley sólo bajo estrictas garantías para asegurar el respeto al "núcleo intangible de la intimidad del afectado" en los términos establecidos por el TCFA en su sentencia de 27 de febrero de $2008^{35}$ : en primer lugar, la instalación del programa espía que llevará a cabo el registro online se hará sin entrar en el domicilio afectado; en segundo lugar, un juez ha de autorizar el registro, que sólo podrá solicitarse en presencia de un peligro concreto de que se van a cometer delitos muy graves ${ }^{36}$; y en tercer lugar, una vez obtenidos los datos a través del registro, hay que garantizar que no se lesiona el derecho a la intimidad del afectado, examen que llevarán a cabo dos funcionarios del BKA y el Director de la Oficina de Protección de Datos de esta Agencia bajo la supervisión en todo caso de un juez. En cualquier caso, la posibilidad de llevar a cabo registros online se contempla en esta ley sólo hasta el año 2020. La ley permite además al BKA, con vistas a la prevención de delitos particularmente graves, la instalación (con autorización judicial) de micrófonos y cámaras en domicilios (incluso en domicilios ajenos al de la persona de la que se espera obtener información); la obtención de perfiles mediante el cruce de datos procedentes de diferentes ficheros; y la escucha y grabación, con autorización judicial, de conversaciones telefónicas, así como la localización espacial de teléfonos móviles.

La nueva ley fue duramente criticada por la oposición y ha sido recurrida en amparo ante el Tribunal Constitucional Federal ${ }^{37}$. En el Acuerdo de Coalición de octubre de 2009 entre democristianos y liberales se dice en relación a esta ley que se modificará una vez que el Tribunal Constitucional Federal haya resuelto dicho recurso. Lo que sí se ha plasmado expresamente en dicho Acuerdo es que, en su caso, los registros online habrá de autorizarlos, no cualquier juez, sino un Magistrado del Tribunal Supremo Federal en asuntos penales (Bundesgerichtshof).

También el Land de Baviera aprobó el 3 de julio de 2008, a través de una reforma de la Ley regional sobre Funciones de la Policía y de las Autoridades de Defensa de la Constitución (Polizeiaufgaben- und Verfassungsschutzgesetz), la introducción de los discutidos registros online de sistemas informáticos practicados sin conocimiento del afectado. Para ello se permite a los investigadores acceder incluso físicamente al ordenador, entrando secretamente en el domicilio del sospechoso, para instalar los dispositivos espía. Sin embargo, en el Acuerdo de Coalición entre la CSU y el FDP, que gobiernan conjuntamente Baviera desde octubre de 2008, se alude expresamente a que aho-

do el peligro no es susceptible de ser localizado en un Land en concreto o cuando no es posible identificar con claridad la competencia de un Land.

35 Véase al respecto MARTíN VIDA, M.A., op. cit., pp. 359 ss.

36 Precisamente uno de los puntos más discutidos, que llevó al veto inicial del Bundesrat, fue el hecho de que la ley previese inicialmente la posibilidad de que en casos de urgencia el BKA pudiese actuar sin intervención judicial, con la autorización del Presidente de la Agencia.

37 "Ex-Innenminister Baum klagt gegen BKA-Gesetz". Spiegel Online, 23 de abril de 2009. 
ra, por exigencia del FDP, el acceso al domicilio del sospechoso para instalar el dispositivo espía quedará prohibido.

- Mucho se ha discutido en estos meses también acerca de la posibilidad de bloquear el acceso a páginas web con contenidos pedófilos, lo que para muchos ha representado un primer intento gubernamental de censura en Internet y una vulneración del derecho fundamental a la libertad de información ${ }^{38}$. El Parlamento aprobó en junio una Ley para Dificultar el Acesso a Contenidos Pedófilos en las Redes de Comunicación (Gesetz zur Erschwerung des Zugangs zu kinderpornografischen Inhalten in Kommunikationsnetzen), que obliga a los proveedores de Internet a bloquear el acceso a determinadas webs de acuerdo con un listado (secreto) que les será remitido por el BKA. La ley prevé que a quien pretenda acceder a una web de contenido pedófilo ubicada en un servidor alemán le aparezca una señal de STOP en la pantalla, lo cual en sí mismo, por otra parte, no conlleva ninguna consecuencia penal, aunque los proveedores han de comunicar al BKA el intento de acceso a la web. Cinco proveedores de Internet habían suscrito meses antes un acuerdo voluntario con el BKA para impedir el acceso a webs de contenido pedófilo. El 8 de octubre de 2009 el Tribunal Administrativo de Wiesbaden (núm. de acta: 6 L 1185/09.WI) obligó al BKA a no remitir sobre la base de estos acuerdos voluntarios ninguna lista de webs a los proveedores de Internet mientras la ley citada no estuviese en vigor por entender que tales acuerdos no podían ser puestos en práctica sin base legal suficiente para ello. El Partido Liberal (FDP) ha conseguido frenar en el Acuerdo de Coalición después de las elecciones al Bundestag de septiembre de 2009 la puesta en marcha de esta ley (que al cierre de este trabajo aún no había sido sancionada por el Presidente Köhler), al menos durante un año, plazo al final del cual se volverá a valorar la situación. La táctica será ahora, durante este año, la de borrar las webs pedófilas en lugar de bloquear el acceso a las mismas. La eliminación de contenidos no plantea problemas dentro de Alemania, ni desde el punto de vista del fundamento legal ( $\$ 184 b$ del Código Penal alemán), ni del de la cooperación de los proveedores con la Policía en la práctica, pero sí que se topa con innumerables dificultades cuando los servidores se encuentran en el extranjero. En esos casos el bloqueo de las webs al menos complica la difusión de los materiales pornográficos ${ }^{39}$.

- El 3 de julio de 2009 aprobó el Bundestag una reforma de la Ley Federal de Protección de Datos, en virtud de la cual los datos personales pueden, a partir de la entrada en vigor de la reforma, ser entregados a otras em-

38 Un análisis de la ley y de los derechos fundamentales afectados en SIEBER, U.: "Sperrverpflichtungen gegen Kinderpornografie im Internet". Juristenzeitung, núm. 13, 2009, pp. 653 ss. También se alega que la competencia en materia de "defensa contra peligros" (acción preventiva contra el crimen) es competencia de los Länder y no de la Federación, por lo que la ley sería también probablemente inconstitucional desde el punto de vista formal.

39 Véase más ampliamente TOMIK, S.: "Sperren, was nicht zu löschen ist". Frankfurter Allgemeine Zeitung, 18 de junio de 2009. 
presas o utilizados con fines de envío de publicidad sólo con el consentimiento expreso y por escrito del afectado, y no como hasta ahora, que bastaba con que el afectado no se opusiese expresamente a ello. Se prevén, sin embargo, numerosas excepciones que suavizarán los efectos de la reforma en este punto. La reforma crea asimismo un sello en materia de protección de datos que permite acreditar a las empresas que lo obtengan como respetuosas con la protección de los datos de sus clientes. Además, tras los escándalos de espionaje de grandes empresas a sus trabajadores, se mejora, como se prometía en el Acuerdo de Coalición entre democristianos y liberales, la protección de los datos de los empleados frente a sus empleadores y se refuerza la posición de los Delegados de Protección de Datos dentro de las empresas.

En materia de protección de datos se espera para la primavera de 2010 que el Tribunal Constitucional Federal se pronuncie acerca de si la conocida como Ley sobre Conservación de Datos, que transpone en Alemania la Directiva comunitaria 2006/24/CE sobre esta materia, vulnera el derecho fundamental a la autodeterminación informativa. La ley ha sido recurrida por treinta y cinco mil ciudadanos en el que es el mayor recurso de amparo de la historia alemana. Hay que recordar que en marzo de 2008 el Tribunal de Karlsruhe adoptó una medida cautelar, en virtud de la cual, mientras se resuelve el recurso contra la ley, si bien se sigue permitiendo el archivo de los datos sobre las comunicaciones (no del contenido de las mismas) por parte de las empresas de telefonía e Internet, las autoridades estatales sólo podrán acceder a ellos cuando se trate de perseguir delitos particularmente graves (en concreto, cuando existan sospechas concretas de asesinato, secuestro o pornografía infantil). En el caso de delitos menos graves el acceso a los datos está vedado hasta que se resuelva el recurso.

- También para 2010 se espera con enorme expectación una sentencia del TCFA (núms. de acta: $1 \mathrm{BvL}$ 1/09 y otros) en la que éste ha de resolver varias cuestiones de inconstitucionalidad planteadas por el Tribunal Federal de lo Social el 27 de enero de 2009 y por Tribunal de lo Social del Land de Hesse relativas a si el procedimiento que establece la ley para calcular la cuantía del subsidio de desempleo (más conocido como "Hartz IV") en el caso de los menores de catorce años que conviven con desempleados (casi dos millones de niños en Alemania) es acorde con la Ley Fundamental o si vulnera el principio de igualdad y el derecho al mínimo existencial, que forma parte de la garantía de la dignidad humana constitucionalmente protegida. La crítica se plantea sobre todo porque en el caso de los niños el subsidio se calcula como un porcentaje del que reciben los adultos, sin tomar en consideración que los niños tienen necesidades específicas que los adultos no tienen ${ }^{40}$.

- Gran eco ha hallado en Alemania, y obligará a una reforma legislativa, la sentencia del Tribunal Europeo de Derechos Humanos dictada el 17 de di-

40 Cfr. HIPP, D.: "Verfassungsrichter bringen Regierung in Erklärungsnot». Spiegel Online, 21 de octubre de 2009. 
ciembre de 2009, que obliga al Estado alemán a indemnizar a un hombre recluido en un centro de internamiento con cincuenta mil euros por haberle aplicado retroactivamente una reforma de la ley penal que amplió indefinidamente su estancia en el centro de internamiento, inicialmente limitada a diez años. El Tribunal de Estrasburgo, donde hay pendientes varios recursos similares (en Alemania hay unas setenta personas en la misma situación que el recurrente), considera que esto constituye una vulneración del derecho fundamental a la libertad. El TCFA había confirmado en febrero de 2004 la constitucionalidad de esta medida por entender que la prohibición de retroactividad de la ley penal no se aplica a las leyes en materia de readaptación social y custodia de seguridad. La ley penal alemana permite recluir a condenados por delitos particularmente graves, que ya han cumplido su condena pero que puedan representar un grave peligro para la sociedad, en centros de internamiento para apartarlos de la sociedad. Al interno que recurrió al Tribunal de Estrasburgo se le condenó inicialmente a permanecer en el centro de internamiento diez años (el máximo que preveía entonces la ley) tras cumplir la condena de cinco que se le impuso por intento de asesinato. En noviembre de 2001 tendría que haber salido en libertad, pero para entonces se había modificado la ley y se permitía recluir de por vida en centros de internamiento a presos peligrosos que ya hubiesen cumplido su condena. Esta ley se le aplicó al interno en cuestión, que no salió en libertad en noviembre de 2001 y sigue recluido hasta la fecha.

- Otra sentencia del Tribunal de Estrasburgo condenando a Alemania por violación del Convenio Europeo de Derechos Humanos se dictó el 4 de diciembre de 2009. Esta sentencia condenó al Estado alemán por discriminar a los padres no casados respecto a los casados: mientras que los padres casados ostentan de manera conjunta con la madre la patria potestad sobre los hijos comunes, en el caso de los padres no casados sólo pueden ostentar la patria potestad respecto a los hijos comunes con el consentimiento de la madre. Si éste falta, no pueden ni siquiera por vía judicial conseguir la patria potestad. Eso vulnera, en opinión del Tribunal, el derecho a que se respete la vida familiar y la prohibición de discriminación. La Ministra de Justicia Leutheusser-Schnarrenberger (FDP) ya ha anunciado una próxima modificación de la ley alemana en este punto.

- La crisis económica y financiera ha sido un tema recurrente en Alemania, como en el resto de Europa, a lo largo de los últimos dieciocho meses. Sin ánimo de exhaustividad hay que hacer referencia a la quiebra del banco Hypo Real Estate, que obligó al Gobierno en octubre de 2008 a poner en marcha un paquete de medidas para garantizar (sin tope máximo) los depósitos de los ahorradores particulares en todos los bancos alemanes y a abrir una línea de crédito de emergencia para salvar al banco, que acabó siendo nacionalizado en agosto de 2009, al adquirir el Estado alemán el noventa por ciento de sus acciones. El Estado alemán asumió también, a través de un Fondo de Estabilización de los Mercados Financieros, la función de garante de los créditos interbancarios e inyectó dinero en el sistema para in- 
crementar el capital propio de los bancos. En diciembre de 2008 se aprobó un programa de medidas por valor de doce mil millones de euros para reactivar la economía (Konjunkturpaket I), al que se siguió en febrero de 2009 un segundo programa con una cuantía de cincuenta mil millones de euros (Konjunkturpaket II), una de cuyas medidas más exitosas ha sido la prima de dos mil quinientos euros que se ha abonado a quien se ha comprado un coche nuevo dando de baja uno de más de nueve años de antigüedad. Y en julio de 2009 se aprobó la llamada Ley de los «bad banks", que permite a las entidades financieras sanear sus cuentas desprendiéndose de activos tóxicos a cambio de un crédito estatal asegurado. También han sido noticia la quiebra de importantes empresas alemanas, como Karstadt-Quelle, y los intentos de salvación de la empresa alemana Opel (que emplea a veinticinco mil personas en Alemania), en manos de General Motors, que justo antes de las elecciones de septiembre, tras meses de negociaciones en las que intervino muy activamente el Gobierno alemán, decidió inicialmente, con el apoyo financiero de Alemania, venderla al consorcio austríaco-canadiense Magna, pero que a principios de noviembre optó por intentar sanearla económicamente ella misma.

- Otro tema que ha dado mucho que hablar en los últimos meses ha sido el rechazo en noviembre de 2009 por parte del Consejo de Administración de la segunda cadena de la televisión pública ZDF, compuesto por representantes de los partidos políticos y representantes de los Gobiernos de los Länder ${ }^{41}$, a la prórroga del contrato del que ha sido redactor-jefe de la ZDF en los últimos diez años, Nikolaus Brender. En el caso concreto el Presidente del Land de Hesse, Roland Koch (CDU), hizo uso de su peso político dentro del Consejo para conseguir que este órgano adoptase esta decisión, al considerar a Brender demasiado poco afín a los intereses de su partido. Esto ha motivado que el Grupo Parlamentario de los Verdes en el Bundestag esté intentando presentar un recurso de inconstitucionalidad ante el Tribunal Constitucional Federal contra la norma (Staatsvertrag) que regula la composición de los órganos de gestión de la ZDF por entender que la libertad respecto a las influencias políticas que se exige constitucionalmente a la radiotelevisión pública no está asegurada si los miembros del Consejo de Administración se designan como actualmente se hace. Treinta y cinco Catedráticos de Derecho Público publicaron en noviembre una carta abierta en apoyo de la libertad de la radiotelevisión pública, criticando la actitud de Roland Koch y la politiza-

41 El Consejo de Televisión de la ZDF lo componen setenta y siete miembros: cinco son designados por la Iglesia Católica, la Iglesia Evangélica y el Consejo Central del Judaísmo en Alemania; tres por la Federación; doce por la dirección de los partidos políticos con representación en el Bundestag; y los cincuenta y siete restantes lo son por los Presidentes de los Länder. El Consejo de Administración de la ZDF lo componen catorce miembros: cinco los designan los Länder; uno es designado por la Federación; y los otros ocho los elige el Consejo de Televisión por una mayoría cualificada de tres quintos de sus integrantes. Sobre la politización de estos órganos véase el interesante artículo de HAHN, W.: "Die Politik muss das ZDF freilassen". Frankfurt Allgemeine Zeitung, 3 de noviembre de 2009. 
ción de decisiones como la de quién ha de ocupar el puesto de redactor-jefe de una cadena pública ${ }^{42}$.

- Por último, el Ejército alemán y su intervención en Afganistán han sido objeto en los últimos meses de una intensa discusión política, sobre todo a raíz del ataque aéreo el 4 de septiembre de 2009 por parte de aviones de combate americanos, bajo órdenes de un coronel alemán al mando de la misión ISAF, a un convoy de caminones cargados de combustible en Kundus. Los camiones habían quedado varados en el cauce de un río y numerosos civiles se habían congregado a su alrededor. Como consecuencia del ataque fallecieron más de ciento cuarenta personas, entre ellas, además de varios guerrilleros talibanes que habían organizado el convoy con el fin presuntamente de perpetrar atentados contra las tropas ISAF, numerosos civiles.

El ataque ha tenido importantes consecuencias políticas, entre ellas la dimisión del entonces Ministro de Defensa Jung (CDU) cuando ya no ocupaba esa cartera, por la política de información acerca del incidente seguida desde su Ministerio (al haber afirmado que sólo había habido talibanes entre las víctimas cuando ya existían informes que confirmaban la muerte de numerosos civiles). Asimismo se ha abierto una Comisión de Investigación en el Bundestag ante la que tendrá que declarar próximamente incluso la propia Canciller Federal. El nuevo Ministro de Defensa zu Guttemberg (CSU), que calificó el ataque a principios de noviembre, al asumir su cargo, como razonable y necesario, afirmó el 3 de diciembre de 2009 que, según se derivaba de nuevos informes que habían llegado a su poder, el ataque había sido militarmente inadecuado, aunque respaldó en todo momento la actuación del coronel alemán que dio la orden de atacar el convoy.

El 3 de diciembre de 2009 el Bundestag prorrogó la intervención del Ejército alemán en la misión de Naciones Unidas para la estabilización de Afganistán, en la que participan cuatro mil quinientos soldados alemanes.

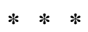

TITLE: German political and constitutional panoramic (july 2008-december 2009).

ABSTRACT. This paper presents the more important constitutional questions discussed and the main constitutional and political events in Germany from July 2008 to December 2009. The author places particular emphasis on the different elections that have taken place in Germany as well as on the reform of federalism concerning the restrictions to get into new debts. Finally this article includes the exam of the Constitutional Court Decisions issued in that period.

RESUMEN: El trabajo presenta una panorámica, sin ánimo de exhaustividad, de los acontecimientos y debates más importantes que han marcado la actualidad política y constitucional en Alemania desde julio de 2008 a diciembre de 2009. En este periodo se destacan, por un lado, las numerosas elecciones que han tenido lugar en Alemania: la del Presidente Federal en mayo de 2009; las elecciones al Parlamento Europeo en junio; la elección del Bundestag en septiembre, que

42 Véase "Der Fall Brender - ein Prüfstein für die Rundfunkfreiheit". Frankfurter Allgemeine Zeitung, 22 de noviembre de 2009. 
ha dado lugar a un Gobierno de coalición entre los partidos democristianos (CDU/CSU) y liberal (FDP); y elecciones en varios Länder, cuyos resultados son decisivos para la articulación de las mayorías en el seno del Bundesrat. Por otra parte, en junio de 2009 se aprobó la segunda parte de la reforma del federalismo, que establece severos límites a la capacidad de la Federación para asumir nuevas deudas a partir de 2016 y lo probíbe a los Länder a partir de 2020. También se hace referencia en este trabajo a diversas sentencias del Tribunal Constitucional Federal alemán que se han dictado en estos dieciocho meses, incluida la emblemática sentencia sobre el Tratado de Lisboa, de 30 de junio de 2009.

KEY WORDS: Germany. Federal constitutional Court. Bundestag. Bundesrat. Elections. Lisbon Treaty. Federalism's reform.

Palabras Clave: Alemania. Tribunal Constitucional Federal. Bundestag. Bundesrat. Elecciones. Tratado de Lisboa. Reforma del federalismo. 